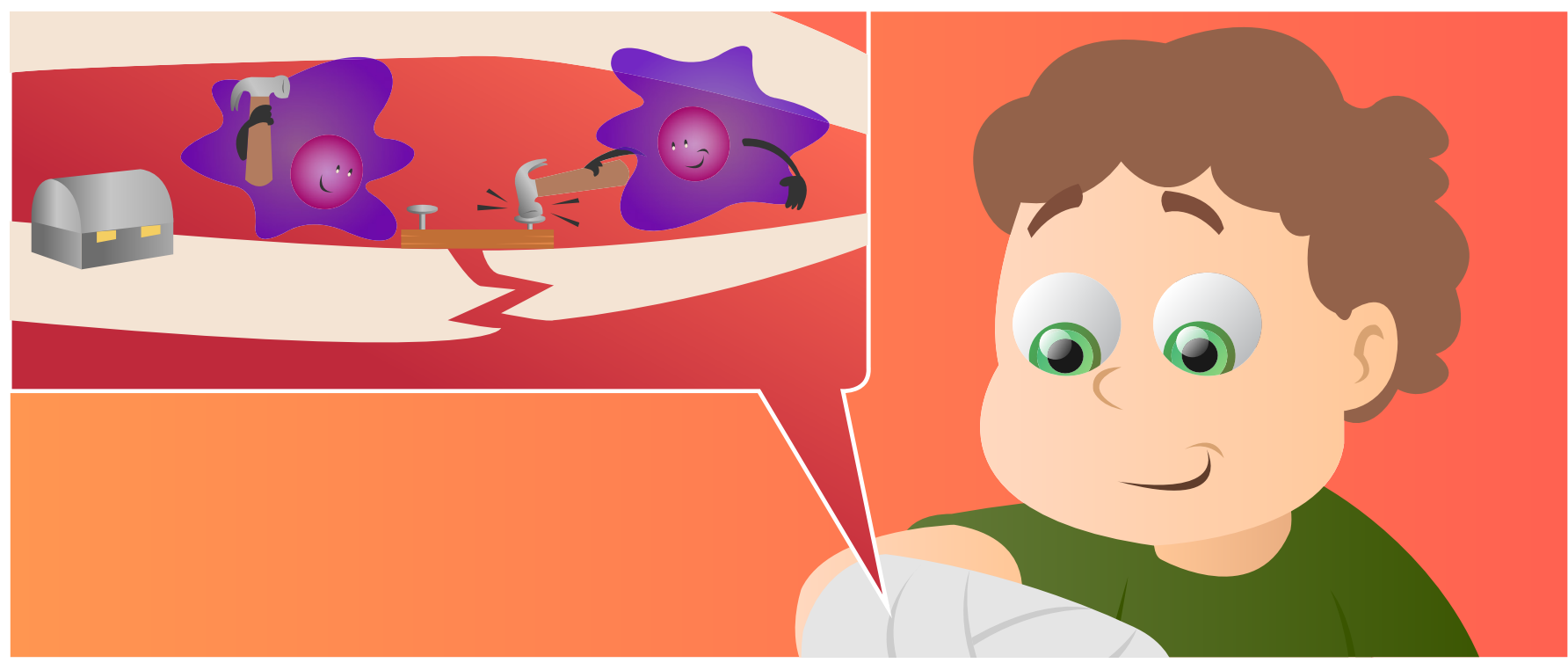

\title{
THE USE OF STEM CELLS FOR TREATMENT OF DISEASES
}

\section{Franka Luk', Elke Eggenhofer' ${ }^{2}$ Marc H. Dahlke² and Martin J. Hoogduijn ${ }^{1 *}$}

'Sector Nephrology and Transplantation, Department of Internal Medicine, Erasmus Medical Center, Rotterdam, Netherlands, ${ }^{2}$ Department of Surgery, University Medical Center Regensburg, Regensburg, Germany

\section{REVIEWED BY: \\ AMAYAH AND \\ KAYLAH}

II AND 9 YEARS OLD
Stem cells are a type of cell that can develop in different ways to form all of the organs in the body, from bone, kidney, and liver to blood and brain. Specialized types of stem cells have the ability to stop immune responses. Stem cells may therefore be very useful as a therapy for diseases in which organs are damaged or where the immune system is too active. Some types of stem cells are already used for therapy, such as the hematopoietic (blood) stem cells, which are used for the treatment of bone marrow cancer. The use of other types of stem cells is currently being studied in the laboratory and in experimental therapies. Researchers are trying to find out the best way of giving stem cells to patients, where the cells go in the body, and how long they survive in the patient. We expect that, in the future, many more stem cell therapies will become available.

\section{INTRODUCTION TO STEM CELLS}

Our bodies are made up of trillions of small units, known as cells. However, at the very early phase of development, we were embryos consisting of only a tiny clump of cells. Cells in an embryo are in a primitive state, and we call them 
EMBRYONIC STEM

CELLS

Cell that can form all different cell types present in the body.

ECTODERMAL STEM

\section{CELLS}

Cell that forms ectodermal cells, such as skin cells, neurons (brain cells).

ENDODERMAL STEM CELLS

Cell that forms endodermal cells, such as lung cells, thyroid cells, and cells of the pancreas.

\section{MESODERMAL}

STEM CELLS

Cell that forms mesodermal stem cells (mesenchymal stem cells and hematopoietic stem cells).

\section{HEMATOPOIETIC} STEM CELLS

Cell that forms red blood cells and different types of white blood cells.

AUTOIMMUNE DISEASES

Disease in which the immune system attacks the own body.

\section{MESENCHYMAL}

\section{STEM CELLS}

Cell that forms fat cells, bone cells, cartilage cells, and muscle cells. embryonic stem cells. Embryonic stem cells can develop into three types of cells, called ectodermal stem cells, endodermal stem cells, and mesodermal stem cells. These three types of stem cells then go on to form 200 different types of cells. For example, stem cells form the cells of your skin, the red blood cells in your blood, and the cells that produce the color of your eyes. Altogether, stem cells form all the organs and tissues in the body, such as the bones, kidneys, liver, blood, and brain. After birth, embryonic stem cells are no longer present in the body.

However, even in the bodies of children, adults, and elderly people, we find several types of stem cells. These stem cells can form some, but not all, of the 200 different cell types. The stem cells present in bone marrow is called hematopoietic stem cells, which are the mother cells of the cells in the blood, including red blood cells that carry oxygen around the body and several types of white blood cells that form the immune system. The immune system is of vital importance for the defense of our bodies against viruses and bacteria. The immune system can, however, also be the cause of disease, for example in autoimmune diseases where the white blood cells attack the person's own body [1]. In the case of organ transplantation, the immune system is responsible for the rejection of the transplanted organ.

Other types of stem cells are found at various locations in the body. In particular, we can find populations of stem cells in organs that usually repair themselves very quickly. The cell layers on the inside of the intestines are renewed every few days by stem cells that are present in the intestines. These stem cells divide and the new cells (called daughter cells) form new layers of intestinal cells. The outer layers of the skin are also continuously renewed, and skin stem cells are responsible for this process. Finally, throughout the body we can find so-called mesenchymal stem cells. These cells form bone, cartilage, fat, and muscle. An overview of the different stem cell types is shown in Figure 1.

\section{EMBRYONIC STEM CELLS}

As mentioned above, embryonic stem cells are present in very young embryosembryos of one-week-old, to be precise. Embryonic stem cells are no longer present in newborn babies. In the future, embryonic stem cells are likely to become an important therapy to repair organs. In the laboratory, we can grow embryonic stem cells into any desired cell type or into small 3D cell clumps that resemble organs, which we call organoids. Cells or organoids can be implanted into organs that are injured as a result of accidents or diseases, where they contribute to the repair of the injury. At the moment, there are still questions about the safety of such treatments, but some initial tests in human have been done to repair damaged eyes with cells derived from embryonic stem cells. The outcome of these studies is important for the development of treatments for other organs. 


\section{FIGURE 1}

Overview of different stem cell types. Embryonic stem cells, in the middle of the figure, can become three other types of stem cells: ectodermal, endodermal, or mesodermal stem cells. Ectodermal stem cells become skin cells and neurons (brain cells), and endodermal stem cells become lung cells, thyroid cells and cells of the pancreas. The mesodermal stem cells form the mesenchymal stem cells, from which fat cells, bone cells, cartilage cells, and muscle cells will form, and the

hematopoietic stem cells, which will form the red blood cells and different types of white blood cells.

\section{IN VITRO}

\section{FERTILIZATION}

A technique that is used to fertilize egg cells with sperm outside the body.

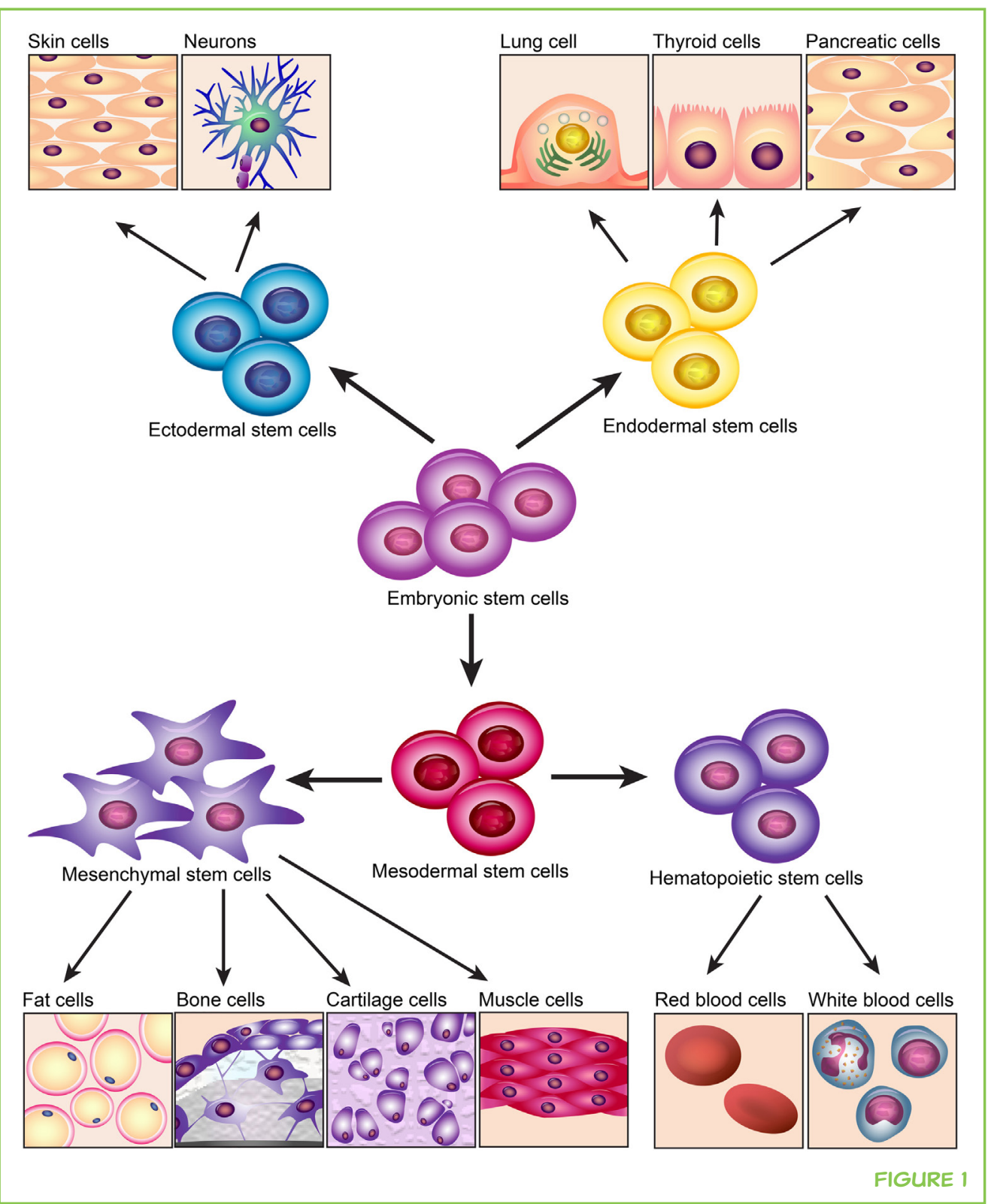

The disadvantage of embryonic stem cells is that they have to be collected from embryos. These embryos come from in vitro fertilization procedures. In vitro fertilization is a technique that is used to fertilize eggs with sperm outside the body. After a few days, the fertilized eggs have formed tiny embryos, which are then placed back into the mother. This is sometimes done for people who cannot easily have children. The embryos that are generated by in vitro fertilization and that are not put into the mother may sometimes be used for the isolation of embryonic stem cells.

There is another method of getting embryonic stem cells that does not involve embryos. In 2006, Professor Yamanaka from Japan discovered a method to turn cells from adults back into stem cells with embryonic stem cell properties. These stem cells are thus capable of forming all 200 cell types, just like the embryonic stem cells, but with the great advantage that no embryos are 
needed for these cells. Professor Yamanaka received the Nobel Prize for his discovery in 2012 !

\section{HEMATOPOIETIC STEM CELLS}

In addition to the embryonic stem cells, there are other types of stem cells that are present in children and adults. The only stem cell type that is widely used today in hospitals as a therapy is hematopoietic (or blood) stem cells. People with bone marrow cancer (leukemia) are treated with chemotherapy to kill all the cancer cells. Due to the treatment, all the important hematopoietic stem cells from the patient will be killed, too. To replace the hematopoietic stem cells after chemotherapy, some stem cells are collected from the bone marrow of patients before chemotherapy and stored in the freezer. After treatment, the hematopoietic stem cells are returned to the patient. These cells will then divide until enough stem cells are present, which will then form red and white blood cells and build a functional immune system. When collecting the patient's own hematopoietic stem cells is not possible, people receive hematopoietic stem cells from a suitable donor.

Other types of stem cells are not yet used for standard therapy, but are being tested as experimental therapies (called clinical trials). Many of these clinical trials are performed with mesenchymal stem cells.

\section{MESENCHYMAL STEM CELLS}

Mesenchymal stem cells are found in any organ you can think of, including bone, fat tissue, lungs, heart, and brain. The function of mesenchymal stem cells is, first, to repair the body by developing into cells that form connective tissue, fat tissue, and bone tissue. Second, mesenchymal stem cells help other cells in the body. They do this by producing compounds that help other cells to survive and to divide. The third function of mesenchymal stem cells is that they can stop immune responses. In the case of an immune response against an infection, mesenchymal stem cells make sure that the immune response does not get out of hand.

The properties of mesenchymal stem cells offer possibilities to use these cells for therapy, such as for the repair of bone fractures that do not heal by themselves or to treat diseases where an overactive immune system causes harm, such as in autoimmune diseases. To do this, mesenchymal stem cells first have to be isolated from tissues. We can do this by removing a bit of bone marrow or a little bit of fat tissue by a small operation and then isolating mesenchymal stem cells from these tissues. The mesenchymal stem cells can then be put in a culture dish. In the culture dish, mesenchymal stem cells divide rapidly so, in a few weeks of culture, large numbers of mesenchymal stem cells can be obtained, which can then be used for therapy (Figure 2). 


\section{FIGURE 2}

Overview of the isolation of mesenchymal stem cells from fat tissue and the possibilities for using these cells to treat diseases. A bit of fat tissue is taken from a patient or a healthy donor in the hospital. In the laboratory, mesenchymal stem cells are isolated from the fat tissue and placed in a culture dish. The mesenchymal stem cells then start to divide, so that in a few weeks enough cells are obtained to treat patients. The mesenchymal cells are given as an experimental therapy to patients with difficult to heal bone fractures, immune diseases, or organ transplants.

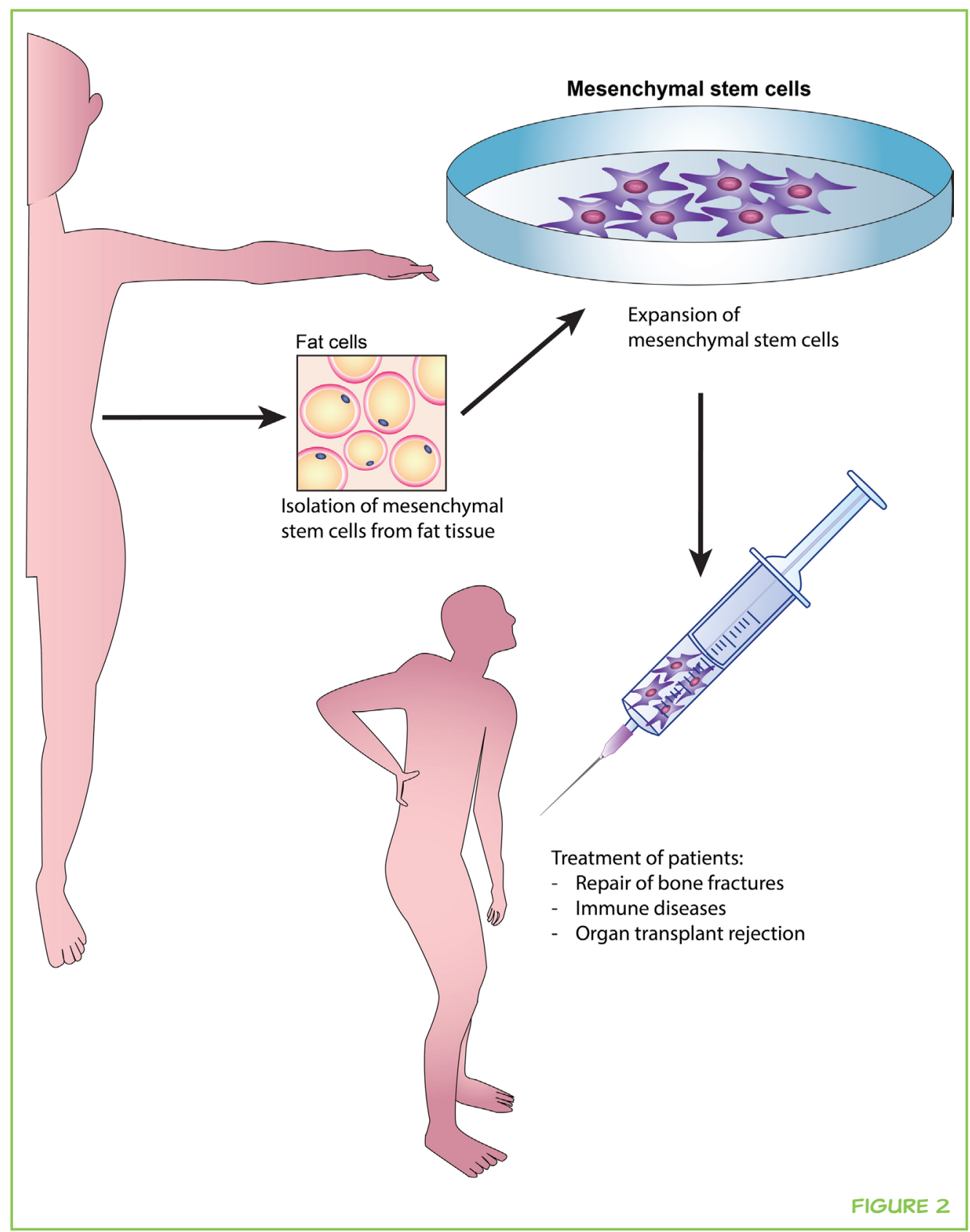

\section{USE OF MESENCHYMAL STEM CELLS TO TREAT DISEASES}

Mesenchymal stem cells are being tested as experimental therapies for a variety of diseases. The way mesenchymal stem cells are given to patients depends on the disease they are used to treat. When mesenchymal stem cells are used for the repair of bone fractures, they are placed inside the bone fracture. The cells are put on a structure that supports the cells. These structures are 3D building blocks with many small pores so that the cells can crawl onto and into the structure. Once the cells are well incorporated in the structure, it can be placed into the bone fracture. In the fracture, the stem cells will form bone tissue and contribute to the healing of the fracture. When mesenchy- 
mal stem cells are used to stop autoimmune responses or immune responses against transplanted organs, they are injected into the blood stream. We have investigated what happens to the cells after they are injected into the blood stream. We found that many of the cells get stuck in the lungs. That is because many of the cells grow very large in the culture dish and can no longer pass through the small blood vessels in the lungs. The lungs filter out many of the mesenchymal stem cells. We also found that many of the stem cells die rather quickly after being put into the blood stream $[2,3]$. Thus a lot of work is required to do to overcome these problems!

\section{CONCLUSION}

There is a lot of research on investigating how stem cells can be used to treat diseases. It is expected that, in the future, stem cell therapies will be developed for many types of diseases for which there are no effective treatments at the moment.

\section{REFERENCES}

1. Davis, R. and Hollis, T. 2016. Autoimmunity: why the body attacks itself. Front. Young Minds. 4:23. doi:10.3389/frym.2016.00023

2. Eggenhofer, E., Benseler, V., Kroemer, A., Popp, F. C., Geissler, E. K., Schlitt, H. J., et al. 2012. Mesenchymal stem cells are short-lived and do not migrate beyond the lungs after intravenous infusion. Front. Immunol. 3:297. doi:10.3389/ fimmu.2012.00297

3. Eggenhofer, E., Luk, F., Dahlke, M. H., and Hoogduijn, M. J. 2014. The life and fate of mesenchymal stem cells. Front. Immunol. 5:148. doi:10.3389/fimmu.2014.00148

SUBMITTED: 11 January 2017; ACCEPTED: 09 March 2017;

PUBLISHED ONLINE: 27 March 2017.

EDITED BY: Fulvio D'Acquisto, Queen Mary University of London, UK

CITATION: Luk F, Eggenhofer E, Dahlke MH and Hoogduijn MJ (2017) The Use of Stem Cells for Treatment of Diseases. Front. Young Minds 5:9. doi:10.3389/frym.2017.00009

CONFLICT OF INTEREST STATEMENT: The author declares that the research was conducted in the absence of any commercial or financial relationships that could be construed as a potential conflict of interest.

COPYRIGHT (C) 2017 Luk, Eggenhofer, Dahlke and Hoogduijn. This is an open-access article distributed under the terms of the Creative Commons Attribution License (CC BY). The use, distribution and reproduction in other forums is permitted, provided the original author(s) or licensor are credited and that the original publication in this journal is cited, in accordance with accepted academic practice. No use, distribution or reproduction is permitted which does not comply with these terms. 


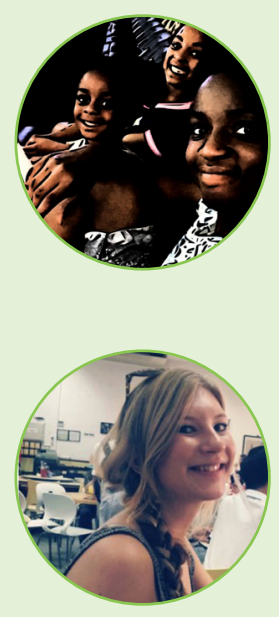

\section{REVIEWED BY}

\section{AMAYAH AND KAYLAH, $\|$ AND 9 YEARS OLD}

Amayah and Kaylah are curious about everything. They also have a younger sister. When not doing school work, they love playing, fashion designing, and watching sports.

\section{AUTHORS}

\section{FRANKA LUK}

My name is Franka Luk, and I am in the final year of my PhD project at the Erasmus medical center in Rotterdam in the Netherlands. I investigate whether we can use stem cells as a therapy for patients that have received a kidney transplant to prevent rejection of the transplanted kidney. My work takes place in the laboratory, where I isolate stem cells from human fat tissue and culture these cells with immune cells that are responsible for rejection of transplanted kidneys. Hopefully this research can contribute to the development of a new therapy for transplant patients in the future.

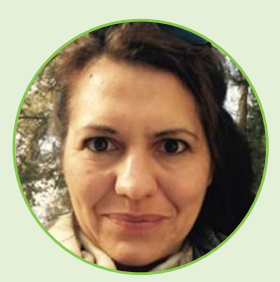

\section{ELKE EGGENHOFER}

My name is Elke Eggenhofer. I am a biologist working in the University Hospital of Regensburg, Germany, Department of Experimental Surgery. I have 10 years of experience working within the field of organ transplantation and stem cells. Transplantation is limited by a scarcity of donor organs and by organ quality. My current research is focused on improving the quality of a donor organ for transplantation in order to improve the situation for people on the waiting lists. Stem cells might be a very good option for it!

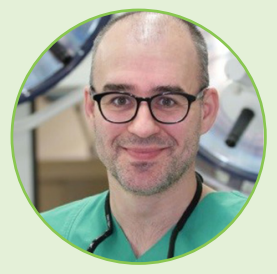

\section{MARC H. DAHLKE}

My name is Marc $\mathrm{H}$. Dahlke, and I am a professor of surgery at Regensburg University Medical Center. In my everyday life, I operate on patients with all kinds of diseases in the belly. In addition to my clinical work, I am part of a research team in the laboratory studying stem cell treatments for patients with surgical problems such as organ transplant rejection or a blood infection called sepsis. I also teach medical students who want to be surgeons or physicians. I find it very effective to be a physician and a researcher together.

\section{MARTIN J. HOOGDUIJN}

I am Martin Hoogduijn. I am a biologist employed at the Erasmus Medical Center in Rotterdam, the Netherlands. With an international team of researchers, I am studying whether we can use stem cells to cure kidney diseases and to prolong the survival of transplanted kidneys. We do this by trying to prevent kidney damage and rebuilding damaged kidneys with the use of stem cells. *m.hoogduijn@erasmusmc.nl 